\title{
A Multidimensional Analysis of Medical Tourism in Shandong Province-Based on Swot Analysis
}

\author{
Zhang Lixia, Lin Qian \\ Shandong Xiehe University, Jinan 250107, China
}

\begin{abstract}
This paper mainly analyzes the advantages of transportation location, resources and industry foundation. At the same time, the disadvantages of inadequate medical tourism development, insufficient R\&D investment and imperfect supervision institutions are analyzed. But the medical tourism of Shandong faces more opportunities for development, such as good momentum of global medical tourism development, preferential policies of medical tourism development in our country, great importance of development of medical tourism attached by government in Shandong, etc., at the same time, it also faces fierce international competition and regional competition pressure. This paper provides reference for the development of medical tourism in Shandong.
\end{abstract}

Keywords-Medical tourism; Swot; Shandong province

\section{INTRODUCTION}

Medical tourism with the theme of restorative care, health tourism, rehabilitation and recuperation has been developing vigorously in the world tourism industry and has rapidly occupied a large share of the global tourism market, becoming a new special industry. Depending on the survey data of the research institute of Stanford university in the United States, the growth rate of global medical tourism is slightly more than twice that of the global tourism industry. In 2017, the consumption quota of global medical tourism industry has reached $\$ 700$ billion, making up about $16 \%$ of the world's total tourism revenues. In addition, tourism is expected to account for 11 percent of global GDP by 2022, with the healthcare industry accounting for 12 percent, according to the world health organization. It can be observed that the research on therapeutic tourism development in China is at the preliminary stage in the face of the advancing medical tourism. At present, only five cities, namely Beijing, Shanghai, xiamen, sanya and taian, are just trying to implement therapeutic tourism products. In view of this, this paper makes a comprehensive analysis of the advantages and opportunities of medical tourism development in Shandongunder the background of aging, and suggests relevant government departments to make good use of these advantages to make up for the disadvantages so that medical tourism development in Shandongwill enter the fast track.

\section{ANALYSIS OF STRENGTH}

\section{A. Location advantage}

Shandongis situated on the east of China, in the lower reaches of the Yellow River. Shandongpeninsula and Korean peninsula have unique strengths of maritime passage, paving China's earliest maritime silk road with significant regional benefits. In the federal "one road and one belt" strategy, Shandongprovince has an important strategic position and role in the implementation and construction of "maritime silk road". Among them, Qingdao, rizhao and linyi have completely overlapped with China's planning of the "new silk" road. These three coastal prefecture-level cities are an important component of the central and western regions of China and the forefront of opening up to the outside world.

The beijing-shanghai expressway runs through dezhou, jinan, Tai'an City and linyi of the province, while the jiqing expressway runs through Shandong peninsula, connecting jinan, zibo, weifang and Qingdao, forming the skeleton of the "T" expressway. The aviation industry has achieved substantial development, Shandong has a total of 8 civil aviation airports, among which jinan remote wall international airport and yantai laishan airport are international airports, among which Qingdao liuting airport is the second largest international airport in east China after Shanghai. Shandong enjoys a good reputation as the "golden coast" of the east. For example, yantai, Qingdao and weihai docks in Shandong have passenger ships to xingang, Shanghai and dalian in China, as well as regular lines to Korea and Japan. That is to say. The superior geographical position of Shandong province and the perfection of the transportation system has laid a solid foundation for the progress of medical tourism.

\section{B. Resource advantages}

Shandonghas the unique advantage of promoting medical tourism resources. Especially in the cultivation of traditional Chinese medicine and rich experience, Shandongprovince has more than a dozen precious materials brand resources. Being a function of statistics, there are about 1,500 kinds of traditional Chinese medicine resources in the province, accounting for more than $10 \%$ of China's traditional Chinese medicine resources, among which, there are about 1299 kinds of botanical traditional Chinese medicine resources. In particular, the yield and quality of flos lonicerae, salvia miltiorrhiza, radix platycodonis, radix codonopsis, radix codonopsis, radix codonopsis, radix codonopsis, radix codonopsis, radix 
codonopsis, and other essential herbs are among the best in China, providing abundant material guarantee for medical tourism in shandong. Weihai city, which is crowned as "the town of hot spring", has the unique feature of accelerating the advance of Shandongmedical tourism industry. Qingdao, the world's living city, has become the only city in China that has been identified as the "world's most beautiful golf" with the title of "the pearl of the yellow sea". It is the better time to visit the island and recuperate from April to November every year, and will certainly win the victory to welcome a large number of domestic and foreign convalescent guests. At the same time, weihai, which the United Nations has honored as the best city for human settlements, is considered to be the home of boiling springs. Weihai hot spring temperature as high as 79 degrees, 17.3 grams per liter vulcanization degree, its composition and the water of the sea near, in addition to containing potassium, calcium, a variety of 20 elements such as tin, iodine, still contain, uranium, radium, radon and other important medical value of trace elements, the chemical composition of the high contain drugs, also are numbered in the country, especially the natural environment of linyi mengshan, negative oxygen ion in the country's first, have a high medical value.

\section{Industry foundation}

Shandongis one of the first five bases of therapeutic tourism development. As one of the four major recuperation bases in China and a provincial health care base for cadres of Shandongprovince, Qingdao nursing home is mainly responsible for providing medical care and rehabilitation for senior cadres of the central organization department, senior cadres of Shandongprovince and academicians of the "two houses" in lu. There are but two places in the world with the billion rehabilitation base, one in Switzerland, and the other in weihai, which ranks fifth among 40 cities in the country in terms of liability. The company independently develops the microorganism Marine ecological medicine bath, which is set in the mountain ecological landscape forest - recuperation forest area, mainly including health club hall, medicine king pool, medicine dining pavilion, food flavor residence, not old forest, medicine king valley and so on. The effect of this medicine bath is a perfect combination of Marine resources and biological pharmacy, giving full play to their respective roles and having certain curative effect on skin, muscle, joint, heart and brain health, as well as promoting blood circulation, reducing inflammation and swelling and pain, delaying aging, improving immunity and improving sleep. Especially bed, mattress, using the latest high-tech jade physiotherapy with magnets and double temperature control physical therapy efficacy, this medical equipment mainly includes medical image of tourism, in vitro diagnostic, electronics, optics, emergency treatment, rehabilitation care and health information technology such as thousands of products, directly to the comprehensive service in medical equipment industry from the source to the end, the whole of both tourism and traditional Chinese medicine and medical industry chain for the extension of TCM and the expansion of tourism, improve the medical care facilities play a key role for the Shandongmedical tourism fast development.
Under the background of high-end medical equipment and abundant medical technology, Shandongremedial system has achieved unprecedented advancement opportunities. At present, there are 42 hospitals in Shandongprovince that have been awarded grade a or above by the ministry of health, among which Shandongprovincial hospital, Qingdao municipal hospital, yantai rehearing hospital, zhucheng people's hospital are the hospital of traditional Chinese medicine and the hospital of integrated traditional Chinese and western medicine and have won the title of "national top 100 hospitals" for many years.

\section{ANALYSIS OF WEAKNESSES}

\section{A. Insufficient development}

Although Shandonghas more therapeutic tourism resources, the development of medical resources is still in the exploration stage. Depending on the author's investigation, most hospitals do not take medical tourism as the advance direction and are basically in the traditional medical model. In addition, the provincial geological survey bureau on hot spring can do detailed statistics. Shandonghas found a total of 78. And the stormy spring facilities included in medical care are only Qingdao jimo hot spring, weihai hot spring and linyi tangtou hot spring. Among the numerous developed and utilized hot springs, only these three have been prepared in terms of physical therapy. Because medical and health hot springs focus on the recuperative functions of boiling springs, they have higher requirements on medical and health facilities and equipment. At present, most hot springs are still in their infancy or embryonic state due to improper development and backward equipment, especially the tourism development of traditional Chinese medicine, which is a long way from the mature stage.

\section{B. Insufficient investment}

For countries with mature development of medical tourism, efficient and rapid advance of medical tourism cannot be achieved without government input. The input includes the capital input and the investment of the professional talent development. As early as 2005, the government of South Korea promulgated the policy on the publicity of medical tourism in remote countries, effectively promoting the vigorous exchange of medical tourism industry in distant countries and in-depth cooperation in product research and development. At present, because of the policy bottleneck, medical care and tourism are independent, so the medical insurance funds can be utilized to medicinal tourism input. In terms of the development of medical tourism in Shandongprovince, in addition to the serious shortage of funds, it has not yet invested in establishing special teams and departments to develop and research independently. At the same time, there is a great lack of investment in medical personnel such as practical experience and medical training. 


\section{Lax supervision}

Because the meticulous rules of macro policies are not perfect, the large-scale development of medical tourism in Shandongprovince is still in the state of no one full-time supervision. Nationwide medical tourism associations have been established in Taiwan, India and South Korea. China and even Shandongprovince are still a blank in this respect, waiting for perfection. In the familial medical market, many institutions, under the name of traditional Chinese medicine, attract foreign tourists, in fact, the product is probably just ordinary health or leisure. The difference between therapeutic tourism and other types of tourism is very big, because medical tourism is a unique and extremely specialized field, which must have a robust theoretical medical foundation. Otherwise, it is hard to know what medicine is bought in the bottle. At present, China's medical market is improving everywhere, showing a brisk expansion trend, but there is not yet a strict and perfect medical supervision system. Government departments must promulgate policies and implement systems as soon as possible to guarantee the safety of patients.

\section{ANALYSIS OF OPPORTUNITY}

\section{A. Quietly rising of world medical tourism}

At present, the progress of medical tourism in the world presents a leap-forward development, from the initial convalescent travel activities gradually expanded to vacation tourism, health tourism, medical tourism and other forms of leisure tourism. In particular, the development of medical tourism in southeast Asian countries has been continuously improved from the mature period to the peak period. With the advance of medical tourism in Europe, America, Africa and other countries, southeast Asian countries have joined the advance medical tourism organization. Emerging countries in the world with medical tourism as the theme of the various types of tourism destinations, such as Switzerland, dubai is given priority to with the high-end and luxury medical tourism services, Hungary, South Korea, the attention health resources to be developed for the purpose of medical tourism, Singapore, Japan and other countries with its high-quality medical resources, form the perfect system of medical tourism destination, Thailand, India, combined with their own economic conditions launch a type of medical tourism destination with lower cost

\section{B. The state and the government strongly support industrial policies}

In February 2016, premier li keqiang organized an executive meeting of the state council to discuss the theme of TCM and tourism. Then, the state council issued the development strategy of traditional Chinese medicine outline (2016-2030) "encouraging" tries to build up in traditional Chinese culture as the center, mainly reflected in the medical rehabilitation, physical therapy, preserve one's health, the health care of the whole traditional Chinese medicine health tourism product demonstration, the government actively participates in the conditional place, the construction of national medical health tourism industry demonstration zone "[2].
In recent years, local governments of Shandongprovince are actively exploring medical tourism resources to maximize the development of medicinal tourism products. Since August 2015, the liaocheng municipal government started its medical tourism journey in liaocheng to build a modern industrial chain of medical tourism in liaocheng and is establishing the initial batch of federal TCM health tourism demonstration base. In February 2016, the Shandongprovince tourism bureau, province administration of traditional Chinese medicine (" TCM health tourism demonstration base in Shandongprovince to assess method (try out) ", "method" regulation, the health of Chinese medicine in Shandongprovince tourism demonstration is divided into three bases: eco-tourism base, cultural tourism base of traditional Chinese medicine of traditional Chinese medicine, Chinese medicine health care services base. In addition, numerous opinions of Shandongpeople's government on promoting health services and tourism development put forward that it is necessary to strengthen the integrated development of health services and medical tourism industry. We will encourage and increase support for medical tourism. Improve facilities for medical tourism projects, and actively think about how to establish a service system for the entire therapeutic tourism industry chain. Efforts to improve health services - based medicinal tourism products to improve the parochial medical tourism market share. It can be seen that the government's emphasis on the development of medical tourism will certainly promote the sound and rapid development of medical tourism.

\section{THREAT ANALYSIS}

\section{A. International competition is constantly expanding}

Under the vigorous promotion of various governments, the competition in this emerging industry market will become more and more intense. The Joint International Commission (JCI) announced that Singapore holds the highest number of medical tourism hospitals in Asia. Singapore hospitals account for one-third of the total of Asian hospitals certified by the joint commission (JCI), representing Singapore with high-end medical technology. In recent years, about 1 million patients from around the world travel to Singapore every year for medical tourism. In order to allow patients to experience the highest curative services in Asia, Singapore provides one-stop service for patients to receive treatment [3]. At the same time, Thailand's medical level, described by its patient population as "first-rate world service, third-rate world price", follows closely behind. Take knee surgery at a Bangkok hospital in Thailand for instance. In addition, there is more complicated coronary artery surgery, which costs as much as 41,000 dollars in the United States, and only costs 1 in 10 dollars to work in the United States, which only costs 4,150 dollars. The postoperative infection is the lowest and the success rate is the highest in the world. "Many hospitals in Bangkok have reached the highest level in the world, giving overseas patients a natural sense of trust," said Steven rush, President of salt medical tourism. Depending on a white paper recently released by CII, a prominent Indian chamber of commerce, the report thinks that the medical tourism market in India will be useful to $\$ 6$ billion by 2018, and will break through $\$ 8$ billion by 2019 . $\mathrm{KPMG}$, one of the big four international accounting firms, 
expects the Indian medicinal tourism market to be worth $\$ 10$ billion by 2020 . It can be seen that medical tourism has spread all over the world, and these countries that took the lead in development have stood out and promoted global medical tourism to be a leapfrog development.

\section{B. Continued high regional competition}

The diversion of domestic tourism from Hong Kong, Macao and Taiwan is a significant challenge to the progress of medical tourism in Shandongprovince. In June 2013, the principal medical institutions and medical beauty brands were recommended in nanjing, allowing nanjing residents to experience quality health check and medical beauty services from Taiwan. Taiwan has world-class medicinal level, ranking the third in 14 out of 200 hospitals in the world. Since the opening of individual tourism to Taiwan in 2017, Taiwan's quality tourism resources have also attracted more and more mainland tourists. In that year, the number of tourists visiting Taiwan for medical tourism reached 120,000 , and it is expected that the number of tourists visiting Taiwan for medical services will increase to 220,000 in the whole of 2018. Hong Kong and Taiwan governments actively promote medical tourism and seek more development of medical tourism on a wider level.

\section{CONCLUSION}

To sum up, the development of medical tourism in Shandongneeds to be improved in many aspects, such as lack of innovative medical technicians, insufficient government input in promoting medical tourism, insufficient cooperation with international organizations and imperfect medical tourism supervisory agencies. At the same time, Shandongis confronted with global and domestic market competition. However, Shandongis a real good opportunity to advance therapeutic tourism. Relying on federal support for industrial policies and the earnest attention of Shandonggovernments at all levels, shandong's medical tourism will be invited to achieve sound and sustainable development with the help of its irreplaceable resource benefits.

\section{ACKNOWLEDGMENT}

Author: Zhang Lixia (1984 -), female, master's degree, main research direction is tourism and hotel management.

Project source: This paper is the development strategy of medical tourism market in Shandongprovince under the background of aging of humanities and social science research project of colleges and universities in Shandongprovince and the possibility and countermeasures of developing medical tourism in Jinan 2015 annual science and technology development plan project (201511068) stage research results.

Project number: J15WB77

\section{REFERENCES}

[1] Developing countries have invested a lot in developing medical tourism. http://life.91sqs.com/html/zazhi/yixuexinwen/2010/0209/835.html.

[2] By the national government for traditional Chinese medicine health tourism policy in http://mt.sohu.com/20160823/n465582289.shtml.

[3] Chen liyu. Overseas medical treatment people come to connect with Singapore to develop medical tourism in Shanghai [N]. Morning news, 2004-11-4.

[4] Global patients seeking medical treatment in India (from global [J], 7th issue, April 6, 2016).

[5] Lai fengwei. Development of Taiwan's emerging industry -- medical tourism [N]. Penghu times, 2015-9-9. 